\title{
El campo de los estudios teóricos de las élites: Notas de investigación en torno a la noción de élite en las escuelas elitistas del siglo XX
}

\section{The theoretical studies of elites field: research notes around elite concept in the elitist schools of the $x x$ century.}

\author{
Nelson Alejandro Osorio Rauld
}

\section{Resumen:}

El presente artículo realiza un recorrido descriptivo y analítico sobre los estudios de las élites, sistematizando críticamente las principales teorías sociales clásicas y contemporáneas del elitismo. El objetivo es proporcionar un balance sobre cómo han sido concebidas teoréticamente las élites revisando el pensamiento de los autores que han analizado la élite como "objeto de estudio sociológico". Así, el investigador social podrá tener una herramienta teórica útil, en la medida en que podrá conocer cuáles son las características sociológicas del pensamiento elitista clásico y contemporáneo, cuáles son las diferencias entre las distintas teorías, además de comprender los límites de cada sistema de pensamiento.

Palabras claves: capital, poder, élite, reproducción social, estructuración

\begin{abstract}
:
This article provides a descriptive and analytical approach to elite studies, trying to arrange the most important classic and contemporary theories on elitism. The purpose of this work is to provide an overview on how elites have been theoretically conceived, focusing on the works of authors who have approached elites as a sociological object of study. This way, the social researcher will have a useful theoretical tool to develop his object of study from

${ }^{1}$ Candidato a Doctor en Sociología por la Universidad Complutense de Madrid. Magíster en Sociología de la Universidad de Chile. Becario de la Comisión Nacional de Ciencia y Tecnología, CONICYT. Autor de Discursos Progresistas y Conservadores en la élite política chilena (ARCIS, 2013) y coautor junto a Tomás Moulian de Tiempos Modernos: Fragmentos de Historia del Chile Contemporáneo (Ayun, 2014).


sociology's standpoint, as he will get to know the main sociological characteristics of both classical and contemporary elitists thought, as well as the differences between the diverse theories while understanding the limits within each thought system

Key words: capital, power, elite, social reproduction, structuration

\section{Introducción}

Estudiar las élites en el campo de las ciencias sociales no es una tarea fácil. Diferentes autores reconocen una cantidad no menor de problemas prácticos para quienes presentan interés en conocer a las élites y sus dinámicas de ejercicio del poder. Uno de las más comunes problemas, sin duda alguna, es la posibilidad de tener entrada a este tipo de agente de la sociedad. Por lo general, se trata de individuos de difícil acceso, sobre los cuales si no existe algún tipo de conexión formal o informal, se hace prácticamente imposible estudiarlos empíricamente, obligando a los investigadores a buscar otras estrategias de investigación (HERTZ \& IMBER, 1995); dentro de las muchas dificultades, también se destaca la relacionada con los aspectos metodológicos, como por ejemplo, la selección de la muestra (Reis y Moore, 2005), pero también la dificultad que supone lograr aprehender las dinámicas sobre cómo se ejerce el poder de las élites, las que muchas veces tienen un carácter formal (observable), mientras que a veces se producen bajos mecanismos complejos de rastrear desde la observación (MOYSER Y WAGSTAFFE, 1987; para el caso chileno véase Cortes Terzi, 2000); En adición, como señalaba el mismo Bourdieu (2001), existe una considerable dificultad en el proceso de "objetivación” de las relaciones de poder, sobre todo cuando el investigador se encuentra sumergido dentro de un campo con una posición dominante, lo que en el fondo pone en evidencia los obstáculos que tienen que eludir los interesados en este campo de estudios.

No obstante, otro problema relevante que se identifica en este campo de estudios, dice relación con la escasa regularidad de los estudios de las élites (SCOTT, 1994; OSORIO 2014 y 2015). Esta discontinuidad está dada principalmente porque la producción teórica de de los pensadores de las élites ha sido un esfuerzo realizado en distintos contextos históricos, lo que sin duda, ha tenido incidencia en la forma en que sus autores han sido concebido a las clases dirigentes: las élites observadas durante la experiencia autoritaria de 
comienzos del siglo XX en Europa, no son similares a las analizadas en el transcurso del apogeo del Welfare State en los Estados Unidos, ni tampoco son símiles a las teorizadas post segunda guerra mundial.

En virtud de lo anteriormente expuesto, a pesar de que la noción de élite se ha hecho popular en la retórica de la política, también siendo bastante utilizada en el vocabulario de las ciencias sociales, ello no necesariamente ha implicado un consenso interpretativo en torno a la definición de élite desde una perspectiva teórica. En otras palabras, el campo de estudios teóricos de las élites ha estado lejos de constituirse en un "programa de investigación" tal cual lo entendió Lakatos (1983), precisamente por la ausencia de un "núcleo" de teorías validadas por la comunidad estudiosa de los agentes más determinantes de la estructura social.

A nuestro modo de ver, esta ausencia de regularidad del campo teórico de las élites podría estar relacionado con actual tratamiento de la teoría elitista, la que ha dejado de funcionar como marco teórico para la comprensión de los agentes con mayor poder causal de la sociedad, lo que sin duda no ha permitido enriquecer la discusión crítica respecto de este concepto (CARASA, 1994).

Pues bien, tomando como antecedente los problemas que rodean al elitismo en su versión teórica, el objetivo de este breve trabajo es poner en evidencia las principales diferencias y similitudes que tienen las escuelas elitistas que se desarrollaron desde comienzos del siglo XX hasta mediados de la década del 70'. Esta comparativa se realiza en torno a 4 ejes de discusión: 1) la noción de élite, donde se describe y analiza cómo los teóricos definían a las élites; 2) los recursos y/o capitales, los que son entendidos como los medios que poseen las élites para poseer la categoría de "minoría selecta" y que son utilizados como mecanismos de estructuración social dominante en el campo en el que se desenvuelven; 3) las estrategias de reproducción social, donde se describen y analizan cuáles son las formas en que las élites buscan permanecer como agente dominante en un determinada posición social; 4) la noción de poder que los autores observan de las élites.

Este cuadro de distinción permitirá distinguir al lector a aquellos elitistas con una concepción unitaria del poder, que denominaremos siguiendo a Aron (1972) como Los 
Monopolistas $^{2}$, cuya tesis se sostiene en la reducción de las relaciones de poder a la imbricación sociológica y política entre una minoría que concentra los dispositivos más determinantes de funcionamiento del poder, y las masas amorfas que carecen de dichos recursos. El segundo grupo que se analiza es aquel denominado como Pluralistas ${ }^{3}$, que se caracteriza por poseer una visión más compleja del poder, el cual se distribuiría en diferentes élites al interior de la estructura social. Para terminar, el presente escrito analiza la teoría de las élites de Raymond Aron y Suzanne Keller, que son los dos últimos pensadores que esbozaron teorías elitistas con pretensión científica de distinto alcance.

En efecto, aun cuando en apariencia este ensayo crítico pareciera no tener un carácter innovador por lo poco actualizada que se encuentra este campo de discusión, la verdad es que cuando se revisa con mayor atención la literatura teórica sobre las élites, se puede apreciar la dificultad con la que se encuentran los investigadores para comprender con mayor precisión la naturaleza sociológica de las élites según las distintas escuelas de pensamiento. En tal sentido, volver a traer a discusión a las diferentes corrientes que informaron la emergencia de las élites como agentes relevantes de la modernización no es, a nuestro juicio, un ejercicio intelectual estéril. Muy por el contrario, su reposicionamiento y particularmente su análisis sobre cómo han sido teorizadas, se podrá concebir como un insumo o "puerta de entrada" para aquellos que pretendan indagar en este campo de producción intelectual.

\section{Los Monopolistas}

Como se puede percibir, los movimientos y acciones de las élites afectan la vida de muchas personas, y esa preocupación de alguna manera ha sido parcialmente incluida en la tradición de las ciencias sociales. Si bien las élites no han sido una preocupación central de la teoría social y política de tal magnitud como otros fenómenos sociales tales como las clases sociales, la modernización, los sistemas sociales, entre otros temas relevantes, importantes intelectuales han tratado de comprender quiénes son los que nos dirigen, con el objetivo de teorizar sobre aquellos que ejercen el poder y cómo lo realizan.

\footnotetext{
${ }^{2}$ Este grupo comprende el pensamiento de Gaetano Mosca, Vilfredo Pareto y Robert Michels.

${ }^{3}$ Este grupo está compuesto por Harold Lasswell, Wright Mills y Robert Dahl. 
Las reflexiones sobre el papel de las élites no son propias de la modernidad, sino que en opinión de algunos autores, se remontan al aporte filosófico de Platón y su concepto de aristocracia como gobierno de los "mejores", así como también al pensamiento de Aristóteles, para quien el "hombre" es un ser cívico por naturaleza y es solamente en la ciudad donde puede alcanzar su plena condición humana, participando en el gobierno de los asuntos públicos. Analíticamente, ello llevaría al autor a relegar la ciudadanía a una condición elitista, por cuanto sólo unos pocos individuos (particularmente el género masculino) pueden acceder a esa condición, mientras la mayoría poseía una condición esclavista (MEIER 1990; KELLER 1971). En esa misma orientación de aporte al campo elitista, Maquiavelo y su obra El Príncipe, constituyen un cimiento de la teoría de las élites donde se puede apreciar una suerte de teoría más elaborada referida a las características que debe tener el gobernante para ejercer el poder y mantenerlo; para ello, Maquiavelo se esmeró en describir las características que debe tener tanto el gobernante o príncipe y también la minoría gobernante que le acompaña (BURNHAM 1945; DAHL 2010: 26).

Pero además de los clásicos mencionados, los pensadores modernos Saint Simón y Comte también esbozaron algunos elementos relevantes para el análisis de las élites. En el primer caso, Saint Simón señaló que era fundamental delegar el poder y la administración del Estado en los productores y jefes naturales, principalmente aquellos sectores identificados con los artesanos y los industriales, relegando la condición de élite a aquellos que poseen características objetivas como "la riqueza" o el capital económico (actualmente el empresariado). Por otra parte, Augusto Comte sentó las bases de lo que actualmente se conoce como tecnocracia, por cuanto para el pensador francés se hacía determinante que los gobiernos estuvieran presididos por una suerte de "aristocracia científica" (Bobbio 2006; Nisbet 1990) como respuesta al estado teológico-tradicional que se dejaba atrás con el advenimiento del capitalismo y la modernidad.

$\mathrm{Si}$ bien todos estos pensadores mencionados aportaron antecedentes y algunos elementos para los estudios teóricos de las élites, su preocupación por el fenómeno elitario no fue central en sus sistemas de pensamiento. El elitismo emerge a finales del siglo XIX e inicios del siglo pasado con Gaetano Mosca, Vilfredo Pareto y Robert Michels. Son estos autores europeos los que sitúan por primera vez a las élites como objeto de estudio científico, sobre las cuales se construyeron teorías que incluso, en los tres casos, llegaron a 
tener el carácter de leyes sociales (OSORIO 2014 y 2015; BOBBIO et.al 2005: 520; GALLINO, 1995 y SCHOECK 1985).

\subsection{La noción de élite monopolista}

El factor común que llevó a Raymond Aron a denominar al pensamiento elitista de Mosca, Pareto y Michels como monopolista, fue la idea de la concentración absoluta del poder político en un grupo, sin una concepción compleja y redistributiva del poder (Aron 1972). En tal sentido, tanto Mosca como Pareto y Michels, observan que es sólo desde el sistema político y sus agentes que se ejerce el poder hacia los distintos campos de la sociedad, y sería la clase dirigente el grupo social con las características ya descritas, el llamado a ejercer ese poder hacia las masas.

Para demostrar este supuesto agencialista de la élite política, los monopolistas se caracterizaron por tener una base empírica para proponer sus teorías de las élites. En el caso de Mosca, el recurso de la historia comparativa lo lleva a una observación longitudinal que le permite aseverar la existencia de minorías que detentan el poder político, y que además, dichas élites configurarían mecanismos de monopolización del poder, tal cual lo afirmó Weber pocos años después haciendo alusión al concepto de Estado burocrático (Bobbio 2006). Para Mosca, la característica esencial de esta élite política de carácter histórico, y que permanece más allá de los vaivenes de los cambios sociales, es la comprensión de una minoría organizada que concentra el poder por sí y para sí, en contraposición a las masas que carecen de la organización por su estructura demográfica, además de no poseer los recursos y las tecnologías que la llevan a ejercer el poder político (Mosca, 2006).

Del mismo modo y con similar afán cientificista, el sociólogo Vilfredo Pareto recurrió a las estadísticas sociales para observar una situación que le permitió configurar parte de su teoría elitista. La observación de una permanente curva de distribución de la riqueza en manos de individuos altamente calificados, en donde el $20 \%$ de la población posee prácticamente todo el patrimonio y los activos económicos, mientras el $80 \%$ se encuentra en una situación de desposesión material. Para Pareto, estos individuos que poseen la riqueza económica son aquellos que en todas las actividades sociales obtienen las mejores calificaciones. 
"en todas las ramas de la actividad humana se atribuye a cada individuo un índice que indica sus cualidades, más o menos del mismo modo que se asignan puntos en los exámenes, en las diferentes materias que las escuelas enseñan. Por ejemplo, asignaremos 10 puntos a quien se destaca en su profesión. Al que no ha conseguido tener ni un solo cliente, le asignaremos 1, con el fin de poder asignar 0 al que es realmente un cretino. A quien supo ganar millones, lo haya hecho bien o mal, le asignaremos 10. A quien gana millares de francos, le atribuiremos 6. A quien apenas consigue no morirse de hambre, le daremos un 1. Al que está hospitalizado en un asilo de indigentes, le daremos 0 (...) y así sucesivamente, para todas las ramas de la actividad humana...por consiguiente, formamos una clase con los que tienen los índices más elevados en la rama en que despliegan su actividad, y asignamos a esta clase el nombre de elite. Cualquier otro nombre y aún una simple letra del alfabeto servirían igualmente para el fin que nos proponemos" (PARETO 1967: 68).

Finalmente, la clase social más alta, se distinguiría entre aquellos que pertenecen a estos sectores acomodados de alta cualificación y la élite política, compuesta por ministros, senadores, diputados, directores generales de ministerios, presidentes de salas de apelación, generales, coroneles, dirigentes de partidos, entre otras altas jerarquías de la administración del Estado.

No con menos rigurosidad académica, el último monopolista, Robert Michels, también recurrió al recurso empírico para enarbolar su teoría de las élites partidistas bajo la tesis de la "ley de hierro de la oligarquía". El trabajo principal de Michels fue su libro Los partidos políticos publicado el año 1911. En este trabajo, el pensador alemán muestra con acuciosidad empírica las tendencias oligárquicas de los partidos políticos modernos, centrando su análisis en el Partido Social Demócrata Alemán, en el cual militó durante largo tiempo. La tesis que subyace a ese trabajo tiene relación con mostrar la imposibilidad del funcionamiento de los partidos políticos en forma sustantivamente democrática, más allá de la retórica revolucionaria y democratizante de sus líderes políticos. Fue esta tendencia insoslayable de la historia de las instituciones modernas que Michels denominó como la "Ley de hierro de la oligarquía" que se expresa de mejor modo en la siguiente afirmación del sociólogo alemán: "La ley sociológica fundamental... puede formularse más o menos así: la organización es lo que da origen a la dominación de los elegidos sobre los 
electores, de los mandatarios sobre los mandantes, de los delegados sobre los delegantes. Quien dice organización dice oligarquía" (MICHELS 1976: 273). En esta concepción de la democracia y de sus líderes, Michels destruye la noción meritocrática de la élite, que por sus condiciones culturales y/o políticas tendría dicha condición de privilegio, atribuyendo a un monopolio de los cargos y a prácticas autoritarias la condición esencial para pertenecer a las grupos dirigentes tanto en los partidos como en toda estructura de poder político.

\subsection{Recursos y/o dispositivos de poder}

Los monopolistas consideraban que los agentes que ejercían el poder político, lo hacían en gran medida por los dispositivos de poder que tenían. Mosca como Pareto, al igual que Michels, consideraban que las élites poseían dicha condición de privilegio porque históricamente estaban constituidas como minorías a través de una distribución desigual de los recursos de poder producida en el origen social; distribución producida desde el momento de su nacimiento (high born), que los configuraba directamente como grupos de poder $^{4}$. En tal sentido, esta adquisición de capitales y recursos desde el origen social, luego serán fundamentales para mantener su posición de privilegio, pero al mismo tiempo para reproducir la estructura de dominación que consolidaría esa posición dominante (OSORIO 2014).

En el caso de Mosca, los recursos de poder están asociados a las distintas especies de capital que tiene la clase política para ejercer el poder: 1) la educación formal en ciencias racionales, la que en el contexto en que escribe el autor, es de un alto costo económico, constituyéndose por ello en un bien escaso valorado socialmente; 2) Una educación moral que el autor denomina como "fórmula política" (MOSCA 2006), y que le otorga a la élite un nivel de superioridad sobre aquellos que no la poseen; 3) Una posición social y económica de privilegio dada por la transmisión de valores y de la herencia del patrimonio; 4) Finalmente, el uso de la fuerza como forma de gobierno, entendida como capital político de autoridad, la que se ejerce contra las masas como mecanismo de control civil.

\footnotetext{
${ }^{4}$ Esta lectura bourdiana de la constitución de las élites permite dar cuenta de que la élite tiene dicha condición porque la transmisión de los capitales y recursos se produce desde el origen social, en forma generacional, y ello le otorgaría el carácter histórico de la posición de élite. Para una lectura bourdiana del elitismo, véase Osorio 2014 y 2015.
} 
Pareto, a diferencia de Mosca, colocó más énfasis en las características psicológicas de la élite que en las propiedades sociales, aunque estas últimas también ponderaban un lugar importante en su pensamiento. De este modo, los recursos de poder de la élite estarían conformados por una piramidal distribución desigual de la riqueza, el talento y la inteligencia. Si bien estos atributos psicológicos (cognitivos) para Pareto son determinantes para la estructuración de las élites, también son complementarios como dispositivos de poder la superioridad económica, política y cultural (ALONSO 1977). Sin todos estos elementos, no sería posible ser parte de las élites tanto sociales como políticas.

El sociólogo Robert Michels, tomaría cierta distancia de esta visión esencialista de las élites asociada a los recursos positivos intrínsecos de los hombres que ejercen el poder político. En cambio, el pensador alemán situaría la condición de élite política en aquellos hombres que productivizan de mejor forma su capital político mediante el uso de la fuerza el poder, la astucia, y el liderazgo político a través del carisma y la retórica demagógica (MICHELS 1975). El "maquiavelismo" latente en los tres monopolistas (EVANS 1994; BURNHAM 1945), cobraría en Michels mucho más significación a la hora de construir su noción elitista, por cuanto el capital político que se describe se orienta principalmente hacia prácticas antidemocráticas y discursos políticos demagógicos con capacidad de convencimiento del electorado a través del carisma para convencer a los votantes, tanto al interior de los partidos como para convencer a las masas amorfas.

\subsection{Estrategias de reproducción de las élites}

Si existe una característica relevante en los monopolistas, a parte de las ya mencionadas, es la idea de reproducción. Esta idea se torna central en los tres autores, por cuanto ella constituye la base de la permanencia en el poder político de las clases dirigentes.

Para Mosca, los mecanismos de reproducción social de las élites están ligados a la transmisión generacional del patrimonio simbólico y económico entre los agentes, siendo este traspaso uno de los dispositivos determinantes para pertenecer a una élite. Tal cual se mencionó, es posible de esta idea de herencia, apreciar la complejidad del pensamiento de 
Gaetano Mosca, por cuanto el autor italiano daba cuenta de una originaria e histórica estructura desigual de recursos que produciría a las élites: capital económico y además buenas costumbres sociales, culturales y familiares que se transmiten de generación en generación, las cuales una vez heredadas constituirían a los agentes sociales en élites (OSORIO 2014 y 2015).

No muy lejos de la idea de Mosca, Pareto se basó en la original idea de la circulación de las élites. En este sentido, la afirmación "la historia es un cementerio de aristocracias" (Pareto 1967), permitiría introducir que ninguna élite permanecería imperecederamente en el poder, y estas circularían constantemente en la medida en que éstos grupos políticos carezcan de las competencias necesarias para ejercer el poder. Para Pareto, esa forma de ejercer el poder sería el equilibrio del uso de la fuerza y de la astucia como condición esencial para mantener las posiciones de privilegio, pues cuando uno de estos elementos falla, se produciría el recambio de los miembros de las élites; rotación que se realiza principalmente entre los dos grupos dominantes: la élite social que tiene altas calificaciones en todas las actividades dónde se desenvuelve y la élite política, que es la llamada a ejercer el poder legítimo. Para Pareto en pocas ocasiones la élite política logra absorber a individuos con características excepcionales cuando estos provienen de las masas, y cuando ello se realiza, la presión social que se ejerce sobre ellos es de tal magnitud que ello lleva al individuo a re-orientar sus prácticas para permanecer como un miembro más de la élite. Sin duda, habría sido este el argumento que llevó a Pareto a criticar el socialismo, por cuanto el proletariado en el poder dejaría de ser proletariado, configurándose en una nueva élite por sí y para sí (BOTTOMORE 1965; Aron 1992).

Finalmente, Michels, contrariamente a Mosca y Pareto, consideró que la élite era una casta cerrada con prácticas orientadas hacia la permanencia en el poder a través del convencimiento del electorado para la elección y reelección. La base de su poder se establecería en la confianza en el conservadurismo de la sociedad ante cambios radicales, frenados por líderes moderados, con discursos y retóricas democráticas pero instalados en las cúpulas de los partidos políticos y en la dirección del Estado. Sus estrategias de conservación y reproducción social se asociarían al convencimiento de los votantes, así como también al control técnico de la información como herramienta clave para monopolizar las comunicaciones, lo que impediría el recambio de los cuadros dirigentes. 
En último caso, las élites partidistas para Michels, buscarían producir la desmovilización social de las masas, y usarían la ideología de la organización política para su propio beneficio (LINZ 1999).

Cuadro comparativo Escuela Monopolista

\begin{tabular}{|c|c|c|c|}
\hline Monopolistas & Mosca & Pareto & Michels \\
\hline $\begin{array}{l}\text { Noción de } \\
\text { élite }\end{array}$ & $\begin{array}{l}\text { Minoría política que } \\
\text { controla el Estado y el } \\
\text { gobierno, y que en } \\
\text { forma organizada y } \\
\text { coordinada } \\
\text { monopoliza el poder } \\
\text { históricamente con } \\
\text { fines de dominación de } \\
\text { las masas }\end{array}$ & $\begin{array}{l}\text { La clase alta se divide } \\
\text { en dos élites: una élite } \\
\text { social con prestigio y } \\
\text { riqueza económica y } \\
\text { una élite política, que } \\
\text { domina el Estado, el } \\
\text { gobierno y los partidos, } \\
\text { y que tiene como } \\
\text { objetivo controlar a las } \\
\text { masas }\end{array}$ & $\begin{array}{l}\text { Minoría política } \\
\text { militante y cerrada } \\
\text { socialmente, que } \\
\text { controla los partidos } \\
\text { políticos con fines de } \\
\text { elección y reelección, } \\
\text { y control sobre las } \\
\text { masas }\end{array}$ \\
\hline $\begin{array}{l}\text { Recursos y } \\
\text { capitales }\end{array}$ & $\begin{array}{l}\text { Capital cultural, capital } \\
\text { económico y capital } \\
\text { político }\end{array}$ & $\begin{array}{l}\text { Capacidades } \\
\text { intelectuales y } \\
\text { cognitivas; capital } \\
\text { político y capital } \\
\text { económico }\end{array}$ & Capital politico \\
\hline $\begin{array}{l}\text { Estrategias } \\
\text { de } \\
\text { reproducción }\end{array}$ & $\begin{array}{l}\text { Transmisión del capital } \\
\text { económico y del } \\
\text { patrimonio simbólico- } \\
\text { cultural: educación, } \\
\text { buenas costumbres } \\
\text { sociales y familiares } \\
\text { que se transmiten de } \\
\text { generación en } \\
\text { generación }\end{array}$ & $\begin{array}{l}\text { Rotación constante de } \\
\text { élites como motor de la } \\
\text { sociedad; uso de las } \\
\text { competencias } \\
\text { intelectuales y políticas } \\
\text { para ejercer el poder; El } \\
\text { equilibrio del uso de la } \\
\text { fuerza y de la astucia es } \\
\text { esencial para mantener } \\
\text { posición de privilegio. } \\
\text { Si estas estrategias } \\
\text { fallan se produce la } \\
\text { circulación de las élites. }\end{array}$ & $\begin{array}{l}\text { Convencimiento } \\
\text { mediante la retórica y } \\
\text { el carisma de los } \\
\text { votantes para asegurar } \\
\text { elección y reelección } \\
\text { en cargos de poder } \\
\text { político; control } \\
\text { técnico de la } \\
\text { información como } \\
\text { herramienta clave para } \\
\text { monopolizar las } \\
\text { comunicaciones con el } \\
\text { objetivo de impedir el } \\
\text { recambio de los } \\
\text { cuadros dirigentes }\end{array}$ \\
\hline
\end{tabular}




\begin{tabular}{|l|l|l|l|}
\hline $\begin{array}{l}\text { Concepción } \\
\text { del poder }\end{array}$ & $\begin{array}{l}\text { Concentración del } \\
\text { poder en la élite } \\
\text { política }\end{array}$ & $\begin{array}{l}\text { Concentración del poder } \\
\text { en la élite política }\end{array}$ & $\begin{array}{l}\text { Concentración del } \\
\text { poder en la élite } \\
\text { política }\end{array}$ \\
\hline
\end{tabular}

(Fuente: elaboración propia).

\section{La Escuela Pluralista}

Dos décadas posteriores a la publicación del célebre libro de Robert Michels, los estadounidenses dieron origen a la Escuela Pluralista de las Élites. Ésta se caracteriza por el análisis de individuos notables en las partes más altas de la estructura social, política y económica. En general, los pluralistas pusieron escaso énfasis en las estrategias de reproducción de las élites, que es un elemento central del elitismo europeo, sin embargo, su énfasis estuvo más bien puesto en definir teóricamente qué son las élites y cuáles son algunos de los alcances de su poder en el marco de las sociedades capitalistas avanzadas. En tal sentido, la escuela norteamericana se erigía como un sistemático esfuerzo de crítica a los monopolistas, bajo la hipótesis de la imposibilidad de mostrar empíricamente que todas las sociedades estaban dominadas por un grupo de hombres en el campo político.

\subsection{Las élites y su compleja distribución del poder}

Veinte años después de terminada la primera guerra mundial, en pleno auge de las experiencias autoritarias en Europa occidental, se comienza a desarrollar en Estados Unidos una nueva escuela elitaria de matriz liberal, y de crítica a la adhesión política al autoritarismo de los primeros autores elitistas. Ella tiene su origen en Harold Lasswell quien publica su principal texto sobre las élites en 1936 ¿Who Gets What, When, How? (1966), momento que el mundo está sacudido por la Guerra Civil española y Estados Unidos está gobernado por Franklin D. Roosevelt, quien realiza políticas intervencionistas en el resto de los países con el objeto de enfrentar el periodo post gran crisis mundial ${ }^{5}$.

\footnotetext{
${ }^{5}$ Una de ellas es la adherencia de Estados Unidos al New Deal que tiene como objetivo reestructurar las relaciones entre Estado y sociedad en Estados Unidos, a raíz de la depresión que afectó con fuerza a ese país.

Revista Juris Poiesis - Rio de Janeiro. Vol.21-n²5, 2018, pg.21- 49. ISSN 2448-0517
}

Rio de Janeiro, 29 de abril de 2018. 
Lasswell es de aquellos autores que no necesariamente tomó a la élite como el eje de sus estudios sociales, ya que sus intereses fueron muy diversos, pasando desde la comunicación hasta la psicología, incluyendo a la ciencia política. Sin embargo, su preocupación política dice relación con un objetivo explícito en sus trabajos: el intento de consolidar un régimen político democrático a través de un conjunto de disciplinas científicas, cuya meta es la materialización de la "dignidad humana" en la teoría y en los hechos (Bachrach 1967). De este modo, Lasswell considera que se hace necesario estudiar a las élites políticas porque el estudio de la política es el campo de la influencia del poder y de los que la ejercen, pues en palabras del autor "los que tienen influencia son los que apoderan de la mayor parte de lo apoderable. Los valores disponibles pueden clasificarse en valores de deferencia, de ingreso y de seguridad. Los que tienen la mayor parte de estos son la élite, el resto es la masa" (Bobbio et.al citando a Lasswell 2005: 522). Para ello, Lasswell propone un concepto de élite que tendrá importancia para la teoría democrática pues está directamente influido por ese horizonte ideológico, aunque igualmente no estará exento de críticas importantes (BACHRACH 1967).

A pesar de que su concepto de élite mutaría posteriormente, una primera definición se asocia a la comprensión colectiva de individuos cuyas características les permitiría poder obtener el mejor partido posible de un valor cualquiera, así como también de la posible manipulación de las masas a través del dominio de un conjunto de representaciones simbólicas (LASSWELL 1966). De este modo, las élites de Lasswell no sólo se caracterizan con la idea de manipulación permanente de las masas -la que obedecería a la influencia de su trabajo previo en el campo de psicopatología y la política (AMONDO 1987)- sino que el recurso de la violencia también sería un medio eficaz para ejercer el poder. En tal sentido, la élite atendería a la vinculación de ambas dimensiones: ciertas características del liderazgo orientado hacia sus propios fines bajo una estrategia de manipulación social como control de las masas, y la violencia como método directo de cristalización de la autoridad.

El giro analítico de Lasswell se produciría en la década del 50', en el cual se desmarcaría de la comprensión de la élite que él mismo dio dos décadas antes: 1) se distancia de la hipótesis de que las características de las élites son relevantes para dirigir a las masas, que como se observó, es un elemento central en la teoría clásica del elitismo, y 
2) descentraliza el poder en distintas élites, concepción básica en el elitismo clásico, donde el poder reside en la clase gobernante o la élite dirigente (AMONDO 1987). De este modo, Lasswell define a la élite como “(...) aquellos individuos que, dentro de un grupo, gozan de mayor poder; la semi-élite, por los que tienen menos poder que los anteriores; la masa, por los que tienen mínimo de poder" (LASSWELL Y KAPLAN 1950: 201). Lo anterior, no sólo produce un cambio en el concepto utilizado de élite, sino más bien atiende a un tipo de ontología distinta, por cuanto la condición de pertenecer a las élites no tendría un carácter meritocrático ni menos relacionado con las características "propias” de la agencia (recursos, dispositivos, capitales), sino más bien, ella estaría dada por el ejercicio del poder, realizado desde una posición en la estructura social, particularmente la pertenencia a un cuerpo político. Es precisamente desde ahí desde donde se participa en la toma de decisiones que involucran a las masas. Y dicha comprensión tomaría una distancia considerable de la noción clásica que remite la noción de élite a los funcionarios de gobierno de una clase política. Por el contrario, Lasswell asume una mayor complejidad en la estructura del poder, donde existirían individuos que tomarían decisiones de poder a diferencia de aquellos que perteneciendo a las altas direcciones políticas, carecerían del poder de tomar decisiones o bien de contrarrestarlas. Ello se resume en la máxima: "no siempre las opciones de aquellos a quienes se denomina funcionarios son severamente sancionadas, a la par que las opciones severamente sancionadas no siempre proceden de los denominados funcionarios" añadiendo que precisamente las élites políticas contienen individuos que son capaces de imponer grandes privaciones" (BACHRACH citando a LASSWELL 1950: 112). Esta última cita permite entrever que la élite no siempre toma las decisiones al interior de una estructura de gobierno, pero sí ella tiene una naturaleza impositiva que afecta directamente aquellos que están muy por fuera de la élite, que es precisamente la masa.

\subsection{Las tres élites de poder y su coordinación de intereses}

A diferencia de su compatriota Lasswell, Wright Mills pocos años después pretende demostrar sociológicamente que la élite del poder monopoliza para sí las formas de poder más importantes de la sociedad moderna. Si en Lasswell lo más determinante es la fuerza y 
la manipulación para ejercer el poder, en Wright Mills la estructura del poder no requiere necesariamente de estrategias de coacción y manipulación psicológica de las masas a través de los medios de comunicación: en cambio, es la posición social del poder arraigada en la milicia, el poder político y la economía, como las grandes instituciones que deciden el destino de millones de personas de estadounidenses, y es de tal forma la naturaleza fáctica de las decisiones de esta élite, que no se requiere de una autoridad vertical y violenta, pues los canales de la democracia y de la representación popular funcionan adecuadamente. Sucede, entonces, que existirían minorías políticas que estarían en una posición más privilegiada en la toma de decisiones que aquellos congresistas elegidos formalmente por la soberanía popular. Sería éste el sustrato de la crítica de Mills: Una sociedad donde las instituciones sociales y políticas funcionan formalmente, pero donde éstas serían impotentes ante el poder detentado por ciertos hombres en el país de los Estados Unidos.

La preocupación sociológica de Wright Mills tiene que ver con una sociedad que está a merced de decisiones absolutamente fácticas. Es pertinente indicar que el contexto donde Mills desarrolla su teoría de la élite es posterior a la segunda guerra mundial, post Nagasaki e Hiroshima; decisiones radicales de poder que en ningún caso pasaron por la soberanía popular, sino que más estuvieron determinadas por lo que él denomina la élite del poder. Ese riesgo fáctico, y que evoluciona conforme pasa el tiempo y la tecnología, preocupa sociológicamente a Wright Mills quien se reflexiona del siguiente modo:

“(...) si creemos que la guerra y la paz, y la miseria y la prosperidad ya no son, precisamente ahora, cuestiones de "fortuna" ni de "destino", sino que, precisamente ahora más que nunca, son dominables, debemos preguntarnos: ¿dominables por quién? La respuesta tiene que ser: ¿por quién sino por los que tienen el mando de unos medios de decisión y de poder tan enormemente ampliados y tan decisivamente centralizados? Entonces podemos preguntar: ¿por qué no lo hacen, pues? Y para contestar a esto, tenemos que conocer el contexto y el carácter de la minoría norteamericana de hoy (MILLS 2007: 32).

Para Mills, estas élites arraigadas en el sistema de poder económico, político y militar, las tres áreas que definen la "política de vida" de millones de personas (en la medida en que impactan directamente en la cotidianidad de esos individuos), no responden a una élite 
histórica e imperecedera en el poder o bien a formas aristocráticas de transmisión del patrimonio simbólico y material, sino que más bien responden a una complejización coyuntural en la administración del poder: el paso de una unificación simple entre instituciones sociales, económicas, políticas y militares hacia una concentración del poder en tres instituciones: política, económica y militar. De este modo, una de las claves para Mills de comprensión de la existencia de una élite de poder, tienen que ver con condiciones estructurales que permiten su existencia: la forma y significado de la elite del poder sólo puede entenderse cuando estas tres series de tendencias estructurales se contemplan en el mundo y momento en que coinciden: El capitalismo militar de las corporaciones privadas existe en un sistema democrático debilitado y formal que encierra un sector militar ya muy político por sus puntos de vista y su conducta. Por lo tanto, en la coincidencia de intereses entre los que dominan los principales medios de producción y los que controlan los instrumentos de la violencia recientemente incrementados; por la decadencia del político profesional y el ascenso al mando político de los dirigentes corporativos y los militares profesionales; por la falta de un auténtico servicio civil adiestrado e íntegro, independiente de los intereses creados. Ello llevaría a una noción de élite manejada por W. Mills muy interesante respecto a sus antecesores: la idea de que la élite del poder, más que una dialéctica de la historia basada en la contradicción entre la élite y las masas, sería una "suerte" de configuración y distribución del poder coyunturalmente situada, correspondiente a ciertas condiciones sociales, económicas y políticas como la sociedad norteamericana, y no necesariamente como el destino y fatalidad de toda sociedad que se oriente hacia la modernización capitalista. En tal sentido, si bien W. Mills comprende que existe una tensión entre las masas y la élite del poder que controla a la población norteamericana, esto es propio del tipo de sociedad norteamericana, de lo que se desprende que bajo otro tipo de sociedad, probablemente puedan existir diversas formas de distribuir el poder de forma menos centralizada. Finalmente, ello pareciera ser el resultado concluyente de un proceso de acumulación económica, una intervención del Estado creciente y un aparato militar dispuesto a erradicar al resto de la humanidad para satisfacer sus propios intereses.

Para finalizar, Mills no niega que exista un origen social noble común al interior de la élite del poder (MILLS 2007: 261), pues de hecho, muchos vienen de los sectores de las 
clases altas más ricos o bien sus padres pertenecieron a los sectores profesionales y de los negocios, sin embargo, no radica en esa razón la base social de su poder: para él, el fundamento racional de su poder, radica en la similitud de los miembros, en las relaciones individuales que estos hagan en forma privada como oficial, en las afinidades sociales, culturales y psicológicas: El origen social, la carrera y el modo de vida de la elite sólo los une.

\subsection{La dispersión del poder y la imposibilidad de su monopolización}

Pero a diferencia de Mills, cuyo objetivo central es denunciar la concentración del poder en tres élites altamente coordinadas, Robert Dahl cinco años después (1961) propone un programa teórico que tiene como fin avanzar hacia la democratización pero particularmente hacia la poliarquía. Ello lo sitúa en aquellos autores que han pensado las élites y su inserción en las democracias liberales. Por ello, su obra está indisolublemente ligada a pretensiones políticas aunque no por ello exentas de críticas, pues el intento de conciliar una teoría política con base de datos empíricos tuvo importantes repercusiones en el campo de las ciencias sociales (Boix 2010). Pero además, es relevante indicar que su trabajo tiene una evolución definida, y donde su publicación Who governs? está enmarcada en un trabajo que tiene algunos antecedentes previos que llevan a Robert Dahl a preguntarse empíricamente por la distribución del poder en la ciudad de New Haven.

Dahl es uno de los pluralistas que han concebido teóricamente a las élites, aun cuando éstas no han sido el objeto central de estudio. Cinco años después del famoso y polémico libro La élite del poder, su libro sobre el poder en New Haven se establece como una respuesta eficaz a la concentración del poder descrita por Mills (SPINRAD 1972; Bobbio et., al 2005), la que a juicio del politólogo mostraba una sociedad decadente y "enjaulada" sin poder de decisión, y con una monopolización del poder enraizada en tres élites muy reducidas, lo que se hacía necesario discutir empíricamente.

Es relevante recordar que Robert Dahl está desarrollando su trabajo luego de la segunda guerra mundial y en plena guerra fría, donde se enfrentaban dos cosmovisiones de mundo, y particularmente, dos regímenes políticos: el régimen comunista dirigido principalmente desde la Unión Soviética y el régimen democrático al cual adhería la 
sociedad norteamericana. Dahl, se afilia a dicha tradición que defiende el mundo occidental con el fin de evitar líderes y gobiernos tiranos, donde la concentración del poder reside en unos pocos, muy próximos a ciertos elementos señalados por los elitistas clásicos, pero de algún modo también presentes en la excesiva concentración del poder que describía Mills, y que en opinión de Dahl, no se ajustaba a la realidad social y política de Estados Unidos. Y si realmente ello era así, debía ser demostrado empíricamente, que es un elemento feble del trabajo de Mills (DAHL 2010; BOIX 2010; Aron 1972; SWEEZY 1960). Es en esa dirección que como respuesta ideológica al marxismo que sustentaba ideológicamente al régimen político soviético, Dahl intenta describir cierta distribución del poder que se ejerce desde la ciudadanía hacia los liderazgos políticos elegidos democráticamente. Para ello se aboca al estudio de la ciudad de New Haven con el fin de demostrar ciertas concepciones que él ya venía desarrollando en textos anteriores.

El concepto de élite de Dahl es una respuesta cuya reivindicación es "derribar" teóricamente dos problemas que amenazan no sólo el campo académico sino también ideológico: 1) La noción elitista del poder de la Escuela Monopolista, pero también la concepción de la élite del poder desarrollada por Mills; 2) contribuir empíricamente al fortalecimiento de una teoría política de mayor envergadura sustentada por el recurso empírico de la distribución del poder concebido en la noción de Poliarquía (Bobbio et., al, 2005; Gallino). Para cumplir con ello, Robert Dahl analiza las consecuencias del proceso de transición de la sociedad agraria de mediados del siglo XIX a la sociedad industrial, y el impacto que produjo sobre la distribución del poder: de una sociedad jerárquica, signada por una suerte de desigualdad acumulativa en la asignación de los recursos sociales, se transita a una sociedad pluralista, caracterizada por la dispersión del poder en una multiplicidad de asociaciones voluntarias (dispersión que, sin embargo, no garantiza la distribución equitativa de los recursos sociales) (DAHL 2010; LEIRAS Y MALAMUD 1994).

Para Dahl, existe un orden céntrico basado en centros de poder, no siendo el campo político y su respectiva élite los únicos llamados a ejercer la autoridad. En estos centros de poder, diferentes grupos luchan por desplegar influencia en ámbitos específicos, lo que lleva a una comprensión distributiva de las relaciones de poder, desafiando con ello directamente los postulados del elitismo clásico. Para ello, Dahl observa empíricamente que 
la oligarquía que concentraba la posición dominante fue cediendo poder a nuevos grupos que se fueron empoderando por cuanto se comenzaban a ampliar los espacios de participación política y apertura democrática. Este cambio condujo a la formación de diferentes grupos de líderes, cada uno con acceso diferenciado a los recursos institucionales que funcionan como dispositivos de poder. En el caso de la ciudad de New Haven, Dahl concluye que ningún grupo tuvo la capacidad de controlar totalmente a la comunidad, por lo que se generó un equilibrio de poderes (DAHL 1961: 10-14). En tal sentido, a diferencia de la lectura del Estado como un aparato de dominación al servicio de los intereses de la clase dominante, Dahl considera que el aparato político se encuentra sujeto a la presión de actores sociales, económicos y políticos que se encuentran permanentemente disputando recursos de poder, lo que supone la conciliación de los distintos intereses entre los grupos que compiten. Ello generaría las condiciones para que exista una política democrática, competitiva y pluralista en las sociedades modernas industriales, que es el contexto donde Robert Dahl está observando dicho fenómeno de pluralidad en la distribución de los recursos políticos (DAHL 2010: 36).

Finalmente, se puede entrever en el trabajo que expone Dahl que precisamente los grupos de interés tienen un impacto en la influencia sobre el poder muy potente, y que incide directamente en la agenda gubernamental (Ruiz 2009). Contra ello, poco pueden hacer los gobernados quienes no cuentan con una capacidad parecida para ejercer un control real sobre las acciones del Estado. Ello lleva a señalar a Dahl que, efectivamente, el concepto de democracia es discutible, y en cambio propone el de poliarquías, las que se resumen en una combinación de liderazgos con control de los grupos de interés sobre los líderes políticos. Ello estriba, en consecuencia, en la imposibilidad de pensar a una élite del poder o una clase política unida y coordinada contra (y a favor también) de los intereses de la ciudadanía.

Cuadro comparativo Escuela Pluralista

\begin{tabular}{|l|l|l|l|}
\hline Pluralistas & Lasswell & Mills & Dahl \\
\hline
\end{tabular}




\begin{tabular}{|c|c|c|c|}
\hline $\begin{array}{l}\text { Noción de } \\
\text { élite }\end{array}$ & $\begin{array}{l}\text { Minoría con poder de } \\
\text { dirección e influencia } \\
\text { que domina a las } \\
\text { masas mediante } \\
\text { recursos de poder, } \\
\text { fuerza, violencia y } \\
\text { manipulación de los } \\
\text { símbolos }\end{array}$ & $\begin{array}{l}\text { Minorías de poder } \\
\text { coordinadas y } \\
\text { organizadas, no formales } \\
\text { ni elegidas } \\
\text { democráticamente en el } \\
\text { sector económico, } \\
\text { político y militar. }\end{array}$ & $\begin{array}{l}\text { Asociaciones } \\
\text { voluntarias con poder } \\
\text { causal que compiten } \\
\text { por la asignación de } \\
\text { recursos de poder en } \\
\text { forma democrática }\end{array}$ \\
\hline $\begin{array}{l}\text { Concepción } \\
\text { y alcances } \\
\text { del poder }\end{array}$ & $\begin{array}{l}\text { Poder redistribuido en } \\
\text { varios grupos de } \\
\text { poder; Dominación de } \\
\text { varias élites en cada } \\
\text { sector de la sociedad } \\
\text { con fines de } \\
\text { dominación de las } \\
\text { masas }\end{array}$ & $\begin{array}{l}\text { Poder redistribuido en } \\
\text { tres élites con fines de } \\
\text { dominación de la } \\
\text { sociedad norteamericana, } \\
\text { cuyo poder tiene alcances } \\
\text { insospechados que van } \\
\text { desde la colocación de } \\
\text { una bomba nuclear hasta } \\
\text { la intervención } \\
\text { diplomático en otro país }\end{array}$ & $\begin{array}{l}\text { Poder redistribuido } \\
\text { socialmente en una } \\
\text { multiplicidad de } \\
\text { asociaciones } \\
\text { voluntarias; } \\
\text { combinación de } \\
\text { liderazgos con } \\
\text { control de los grupos } \\
\text { de interés sobre los } \\
\text { líderes políticos; } \\
\text { imposibilidad de } \\
\text { dominación absoluta } \\
\text { de una asociación } \\
\text { sobre otra asociación }\end{array}$ \\
\hline
\end{tabular}

(Fuente: elaboración propia).

\section{Los postclásicos: La teoría de la clase gobernante de Raymond Aron}

En 1953, en medio de la guerra fría que divide al mundo entre socialistas y capitalistas, Raymond Aron realiza una revisión del elitismo, al que cuestiona por su naturaleza inherentemente ideológica, afines a las experiencias autoritarias de comienzos del siglo XX en Europa occidental. Para distanciarse sociológicamente de esa carga valorativa, propone en cambio, una distinción teórica relevante para el análisis de las élites: la élite, la clase política y la clase gobernante. Con esta distinción teórica, Aron es el primer autor en situar las relaciones de poder entre la esfera política, económica y social con sus respectivos agentes, sentando parcialmente las bases para una teoría crítica elitista que desafortunadamente no ha sido desarrollada a la fecha en el campo de la sociología de las élites. 
De este modo, el sustrato del aporte de Aron se dirige a dos problemas teóricos: 1) la colocación en evidencia de que la esfera del poder es compleja y de la existencia de múltiples tipos de relaciones entre los distintos grupos de poder en el marco de las sociedades capitalistas avanzadas; 2) Una crítica teórica el reduccionismo marxista de la teoría de clases que sustenta al régimen soviético de partido único (ARON 1972; VILLA 1994).

Para realizar los dos ejercicios teóricos mencionados, Aron redefine algunos conceptos para referirse a los grupos que disputan el poder colocando especial atención en las relaciones que se producen entre las minorías que lo ejercen. En tal sentido, para el sociólogo francés, el concepto de élite, utilizado en la tradición del elitismo monopolista y pluralista, posee un sentido amplio que puede ser rescatado porque en forma genérica hace mención a aquellos individuos que en la escala de jerarquías están en las posiciones más altas, ocupando puestos de privilegios, ya sea de riqueza o de prestigio. Esta élite operaría mayormente a nivel social, y sería un agente importante para disputar el poder con lo que Aron entiende como clase política (Ruling class), que sería aquella minoría selecta que ejerce las funciones políticas del gobierno y del estado (Aron 1972: 18). Finalmente, en esa disputa por el poder, entre la clase política y la élite social, se sitúa la clase gobernante: agentes privilegiados en la estructura social que no ejercen directamente el poder político pero que tienen, a través de diversos mecanismos y recursos, gran capacidad de influencia sobre aquellos que gobiernan, y sobre todo contra aquellos que sólo obedecen.

Para Aron, la estructura de la clase gobernante está dada por dos elementos sociológicos relacionados con el origen social que la sociología debería estudiar empíricamente: la autoridad moral que le permite estructurar una posición privilegiada, pero también la posesión del poder económico a través de la riqueza, el patrimonio y las finanzas. De este modo, esta estructura está asociada a la complejidad de las sociedades modernas y capitalistas, la que radica en la profesionalización de las funciones, tanto de la clase política profesional que domina y controla el campo político, como aquella clase que está por fuera del aparato de los partidos políticos y del Estado, situándose más bien en la esfera de la sociedad civil (que Aron comprende hegelianamente). Es así que inevitablemente existen relaciones entre todas las clases políticas y las clases gobernantes (entre el Estado y las organizaciones de sociedad civil), y para dar cuenta de esas 
relaciones, la sociología debería abocarse a entender y conocer cuáles son los elementos que estructuran el poder de la clase gobernante. Para ello, Aron propone distinguir algunas categorías sociales de estos grupos complejos de poder que operan por fuera del gobierno y del Estado, pero que se relacionan directamente con la clase política con fines de dirección del poder o de influencia sobre éste. Estas categorías sociales descritas por Aron se relacionan con las antítesis clásicas de las sociedades modernas que tienden a la diferenciación social: poder temporal-poder espiritual; poder civil y poder militar; poder político y poder administrativo; poder político y poder económico. En el caso del poder espiritual-temporal, el papel que juegan los ideólogos, los escritores, los intelectuales, los sacerdotes, las autoridades eclesiásticas, los profesores, entre muchos otros, son relevantes como elementos que estructuran parte de la clase gobernante (esfera civil). Pero también disputan espacios de poder aquellos civiles que eligen a sus representantes, siempre y cuando el poder militar y policial se subordine al poder civil. Del mismo modo, el poder administrativo domina al poder ciudadano, por cuanto las normas impersonales y privadas de carácter político, son dictadas por los funcionarios, y obligan a todos los miembros de la sociedad a respetarlas. Finalmente, en esta relación entre poder político y poder económico, existe una lucha de agentes privilegiados sobre la cual todos intentan imponer sus términos: un primer grupo de directores del trabajo colectivo, propietarios de los medios de producción, directores e ingenieros, y un segundo grupo de adversarios que se expresan en líderes de las masas, jefes de sindicato, jefes de partidos políticos, entre muchos otros.

Para Aron, que está preocupado de teorizar sobre la constitución de las clases gobernantes y su relación con el poder en las sociedades avanzadas, estas figuras recién descritas existirían en todo tipo de régimen, ya sea capitalista o soviético. Sin embargo, la complejidad de organizaciones y grupos de poder por fuera del campo político se da con mucha más fuerza en sociedades capitalistas liberales, porque estas permiten la existencia y el diálogo entre entre los distintos agentes que componen la clase gobernante; se permite también, la existencia de múltiples conflictos e intereses en disputa, pero lo más importante, son los niveles de solidaridad los que estructuran a la clase gobernante, la que en el marco de las libertades civiles, pueden reunirse y asociarse en lugares comunes, adquiriendo conciencia de la comunidad que constituyen, la que en muchas ocasiones se consolida con prácticas de "cierre social” a través de la unión de lazos familiares mediante estrategias 
matrimoniales y otras formas de exclusión con orientación hacia la solidaridad endógena. Sería esta una de las razones por la que Aron insiste en que la sociología debería comprometerse en dar a conocer cómo piensa la clase gobernante, además de entender cuál es la conciencia de solidaridad entre los miembros de este estrato.

Para terminar, esta forma de concebir las relaciones de poder de las élites lleva a Aron a cuestionarse sobre la pugna de intereses que existen entre los múltiples agentes que están por fuera del campo político pero que constituyen la esfera civil, y su relación con aquellos que gobiernan, para saber si, en última instancia, están representados todos los intereses de la clase gobernante en el momento de la toma de decisiones o si se impuso unilateralmente la voluntad de uno de los tantos agentes que disputan el poder.

\section{Las élites estratégicas de Suzanne Keller}

En 1963, dos años después del estudio del poder en la ciudad de New Haven realizado por Dahl, la socióloga Suzanne Keller publica su libro Beyond the ruling class (Más allá de la clase dirigente (1971)), que es el segundo intento real de relacionar la teoría sociológica y la teoría de las élites. De algún modo, este intento había sido realizado por Pareto, quien construyó una teoría sociológica sobre el equilibrio de la sociedad en la cual las élites jugaban un papel fundamental a través de la circulación de los grupos privilegiados como motor del sistema social, pero en cambio, el trabajo de Keller posee una pretensión teórica menos ambiciosa: más que construir una teoría general de la sociedad, su objetivo está asociado a diseñar la arquitectura de una teoría de las élites que permita al interesado en estudiar los grupos privilegiados, contar con una teoría moderna de los grupos que ejercen la dirección social en las sociedades avanzadas.

Keller, al igual que Raymond Aron, Wright Mills y Robert Dahl, está escribiendo en un contexto de guerra fría radical, pero además, en un momento en que las ciencias sociales están atravesadas por dos paradigmas opuestos: el marxismo leninismo y el estructural funcionalismo; es ésta última teoría general de la sociedad la que la autora vincula con las élites estratégicas en el marco de las sociedades capitalistas avanzadas como la norteamericana y el norte de Europa. 
A pesar de ello, Keller, introduce una distinción no realizada hasta ese momento en los autores elitistas, que es la consideración de las élites estratégicas como el instrumento más eficaz de las clases dirigentes. Es en este pensamiento donde se puede apreciar una diferenciación entre la noción de clase social y el concepto de élite, no entendiendo ambas categorías como equivalentes sino más bien como complementarias. Para Keller "las elites estratégicas son cristalización, por un proceso subsiguiente, de las clases dirigentes. No pueden, por consiguiente, considerarse como equivalentes funcionales, sino como alternativas estructurales de las clases dirigentes y de las castas y como representantes de una forma de dirección social más especializada y avanzada” (KELLER 1971: 35) ${ }^{6}$.

La teoría de las élites estratégicas realiza un giro teórico significativo con respecto a los monopolistas y los pluralistas, considerando que las élites poseen esa posición de poder a través de un camino meritocrático y en ningún caso en base a la transmisión del patrimonio, ni al capital político ni menos al linaje. De este modo, erradica el carácter aristocrático de la élite, y la asocia más bien a un grupo cuya procedencia es abierta e interclasista; lo determinante de las élites estratégicas es el lugar que ocupan en la estructura socio-ocupacional y sobre todo, su función estratégica de dirección social; ello lleva a estos grupos a mimetizarse con los dueños del capital, en la medida en que asumen la dirección social y económica resguardando los intereses y objetivos de la misma clase propietaria, lo que a veces lleva a los analistas sociales a confundir ambos grupos de poder. Las élites estratégicas surgen en el contexto de sociedades que tienden a la complejidad de las funciones y a la diferenciación social. Por ello, para Keller, existen múltiples élites estratégicas ubicadas en los distintos sistemas que conforman el sistema social (social, económico, cultural, político); en todos estos sistemas existe la alta dirección de las élites estratégicas, puestos que ellas emergen de la necesidad de dirigir los procesos de modernización de distinta naturaleza. En tal sentido, sus funciones son altamente elaboradas y especializadas. Es por ello que, a pesar de que existen distintas élites estratégicas arraigadas en prácticamente todas las dimensiones que comprenden las

\footnotetext{
${ }^{6}$ Sería Nicos Poulantzas quien unos años más adelante vendría a reflexionar sobre la relación entre las clases sociales y las élites, señalando que: "si la teoría de la élite nace como crítica al marxismo y la noción de determinismo económico, ella misma cae en dicho determinismo al considerar esta unión de élite económica y élite política bajo una misma élite de ricos: "el funcionamiento político del aparato de estado es absorbido en la pertenencia de sus individuos, paralelamente a las otras élites, a ese centro unificador que sería un grupo de rentas elevadas" (Poulantzas 1998: 431).
} 
sociedades avanzadas, para Keller, estos son grupos de poder son muy reducidos y concentrados. Ello la diferencia, por ejemplo, de la clase política, la que está compuesta por una extensa cantidad de individuos que ejercen el poder político: parlamentos, partidos políticos, ejecutivo, gabinetes ministeriales, etcétera. Más bien, como su naturaleza es concentrada, básicamente por sus competencias profesionales de alta dirección social y económica, su duración en las estructuras de poder se remite a tiempos breves sujetos a la realización de sus labores en forma eficaz. Si esto no es así, las élites estratégicas sufren un recambio por grupos profesionales especializados y con dotes de dirección social y económica. Es por ello que, su legitimidad dentro del funcionamiento de la sociedad está dada por las competencias y conocimientos que tienen, los que son escasos y socialmente valorados. Esta consideración, las distancia de las clases dirigentes cuya legitimidad está más bien dada por una razón burocrática y/o la elección popular o bien por por su capital económico y patrimonial.

Finalmente, la noción de poder de Keller se diluye en múltiples grupos que ejercen la dirección en nombre de y acorde a los intereses de las clases dirigentes, lo que posiciona s teoría en forma muy cercana a la clase gobernante de Aron. En estos dos últimos autores, ya es posible observar que existe una comprensión sociológica y política de vinculación social entre intereses interclasistas y élites, lo que lleva a una comprensión crítica del poder y sus agentes, abriendo el espectro de análisis para la investigación sociológica entre las distintas élites y sus intereses.

Cuadro comparativo Teorías post-clásicas.

\begin{tabular}{|l|l|l|}
\hline $\begin{array}{l}\text { Teorías } \\
\text { postclásicas }\end{array}$ & Aron & Keller \\
\hline $\begin{array}{l}\text { Noción de } \\
\text { élite }\end{array}$ & $\begin{array}{l}\text { Múltiples grupos de poder: } \\
\text { élite, clase política y clase } \\
\text { gobernante. }\end{array}$ & $\begin{array}{l}\text { Élite como instrumento de la } \\
\text { clase dominante. }\end{array}$ \\
\hline $\begin{array}{l}\text { Recursos y } \\
\text { capitals }\end{array}$ & $\begin{array}{l}\text { Capital político, capital } \\
\text { económico, capital social y } \\
\text { capital cultural }\end{array}$ & $\begin{array}{l}\text { Capital cultural: competencias } \\
\text { técnicas y profesionales de } \\
\text { conocimiento especializado en } \\
\text { puestos de dirección social }\end{array}$ \\
\hline
\end{tabular}




\begin{tabular}{|l|l|l|r|}
\hline Concepción & Poder situado y redistribuido & Múltiples élites en todas las \\
$y$ alcances & en la esfera política, & esferas que componen la \\
del poder & económica y social. Campos & sociedad capitalista; compiten \\
& de disputa por el poder y de & por el poder de dirección \\
& sus agentes en el marco del & político y económico y aseguran \\
& capitalismo avanzado. & la permanencia y reproducción \\
& & de los intereses de las clases \\
& & sociales dominantes.
\end{tabular}

(Fuente: elaboración propia).

\section{Reflexiones finales}

Es posible apreciar que en la teoría de las élites que va desde Mosca hasta Keller, la categoría de élite, en sus más variadas acepciones, está directamente relacionada con la noción de poder causal y determinante; ésta última categoría como se puede observar, también posee un carácter complejo, por cuanto ella no puede ser reducida únicamente al concepto de Estado y de política en el sentido tradicional o weberiano. En tal sentido, la evolución del elitismo tiene que ver con el reconocimiento de la complejidad del poder y de sus agentes; desde la traspaso de la herencia material y simbólica hasta el camino meritocrático, las élites unidas o dispersadas socialmente, ejercen el poder hacia las masas, aseguran su permanencia en el poder y reproducen estructuras sociales que resguardan sus posiciones de privilegio.

A pesar del sesgo ideológico que poseen los monopolistas, adherente a las estructuras políticas autoritarias de inicios del siglo XX en la Europa Occidental, la idea de reproducción social parece ser la más desarrollada por Mosca, Pareto y Michels; este concepto permitiría, según esta interpretación, poder comprender cuáles son las principales estrategias de perpetuación en el poder y de recambio de las élites, además de los procesos de producción y reproducción de las élites en posiciones de dominación.

Del mismo modo, los pluralistas, cuyo último fin era el fortalecimiento de las democracias liberales y junto con ello, la descentralización del poder en distintos agentes, proporcionan una visión compleja del poder, el que estaría distribuido en las distintas dimensiones de la sociedad, sin necesariamente que un grupo pueda ejercer la coacción total al resto de los agentes sociales con poder causal. 
Finalmente, las teorías elitistas de Raymond Aron y Suzanne Keller, que son las dos últimas teorías elitistas con alcances meta-teóricos, proporcionan los elementos críticos para una comprensión sociológica del fenómeno del poder y de quienes lo ejercen causalmente hacia las masas, incorporando la noción de clase social y de sus intereses objetivos. El aporte, sin duda, radica en la comprensión crítica y utilitarista de las élites, las que serían proclives a defender y movilizar los intereses de agentes asociados expresados en la clase dirigente o en su defecto a la clase gobernante descrita por Aron.

\section{Referencias bibliográficas}

Alonso, Jorge. (1977) Pareto, México D.F.: Editorial Edicol.

Amondo, Gabriel. (1987). Harold Dwight Lasswell. A biographical memoir. Washington D.C.:National Academy of Sciences

Aron, Raymond. (1972). "Clase social, clase política y clase gobernante”. Pp.1-32 en Clase, status y poder, tomo II, editado por Reinhard Bendix y Seymour Lipset, Madrid: Editorial EuraméricaS.A.

Aron, Raymond. (1992). Las etapas del pensamiento sociológico. Buenos Aires: Ediciones Siglo XXI editores.

Bachrach, Peter. (1967). Crítica de la teoría elitista de la democracia. Buenos Aires: Amorrortu editores.

Bobbio, Norberto, Matteucci, Nicola y Pasquino, Gianfranco. (2005). Diccionario de política,. Buenos Aires: Siglo XXI editores.

Bobbio, Norberto. (2006). Estado, gobierno y sociedad. Por una teoría general de la política. México D.F.: Fondo de Cultura Económica

Bottomore, Thomas. (1965). Minorías selectas y sociedad. Madrid-Santiago: Gredos S.A. y Grijalbo Ltda.

Bourdieu, Pierre. (2001). El campo político. La Paz: Plural Editores.

Boix, Carles. (2010). “Presentación”. Pp. 1-25 en ¿Quién gobierna? Democracia y Poder en una ciudad estadounidense de Robert Dahl. Madrid: Centro de investigaciones sociológicas. 
Burnham, James. (1945). Los maquiavelistas. Buenos Aires: Emecé editores.

Dahl, Robert. (2010). ¿Quién gobierna? Democracia y poder en una ciudad estadounidense. Madrid: CIS.

Evans, Mark. (1994). From Machiavelli to mann: some critical reflections of theory. Nueva York:University of York Press.

Hertz Rosanna y Imber Jonathan. (1995). Studyng Elites Using Qualitative Methods, California: Sage Focus Edition.

Keller, Suzanne. (1971). Más allá de la clase dirigente. Madrid: Tecnos.

Lasswell, Harold. (1966). Who gets what, when, how?, Cleveland: The world publishing company.

Lasswell, Harold y Kaplan, A. (1950) Power and society. New Haven: Yale University press.

Leiras, S. y Malamud, A. (1994) "La evolución de la idea democrática en el pensamiento de Robert Dahl". Pp.108-126 en La democracia en el pensamiento contemporáneo, Tomo1, compilado por Julio Pinto. Buenos Aires: CEAL.

Linz, Juan. (1998). Michels y su contribución a la sociología política. México D.F.: FCE.

Meier, Christian. (1990). The Greek Discovery of Politics. David McLintock, Cambridge: Harvard University Press.

Michels, Robert. (1975). Los Partidos Políticos. Un estudio sociológico de las tendencias oligárquicas de la democracia moderna. Buenos Aires:Amorrortu.

Mills, C.B. Wright. (2007) La élite del poder. México D.F.: FCE.

Moyser George \& Wagstaffe Margaret. (1987). Research Methods for Elite Studies, London: Allen \& Unwin.

Mosca, Gaetano. (2006) La clase política. México D.F.: FCE.

Nisbet, Robert. (1990). La formación del pensamiento sociológico. Buenos Aires: Amorrortu editores.

Osorio, N. Alejandro. (2014) Hacia una sociología de las élites. Una revisión crítica del elitismo clásico de Mosca, Pareto y Michels. Tesis para optar al grado de Magíster en Ciencias Sociales de la Universidad de Chile, Santiago de Chile. 
Osorio, N. Alejandro. (2015) "Dominación y reproducción de las élites. Lectura sociológica del proceso de estructuración de las minorías selectas en el elitismo clásico", Revista de investigaciones Políticas y Sociológicas, núm. 2, volumen 14, Universidad Santiago de Compostela,pp. 113-130

Pareto, Vilfredo. (1967). Forma y equilibrios sociales. Madrid: Editorial Revista de Occidente S.A.

Reis, Elisa, y Mick Moore. (2005). "Elites, Perceptions and Poverties" En Elisa Reis y Mick Moore, Elite Perceptions of Poverty and Inequality. London: CROP/Zed Books, pp.125 .

Ruiz, Joel. (2009). "Teoría política norteamericana sobre las élites. Su vigencia en el contexto político y económico actual" en Revista Espacios Públicos, Vol., 12, número 26, diciembre, Universidad Autónoma del Estado de México, México: 169-189

Spinrad, Williams. (1972). "El poder en las comunidades locales" Pp. Pp.33-52 en Clase, status y poder, tomo II, editado por Reinhard Bendix y Seymour Lipset, Madrid: Editorial EuraméricaS.A.

Sweezy, Paul. (1960). "Power elite or ruling class?" en Monthly Review, Pamphlet series, número 13 , New York.

Villa, Juan. (1994) "Clases y élites en la investigación: algunas reflexiones teóricas y metodológicas”. Pp.11-24 en Elites: prosopografía contemporánea compilado por Pedro Carasa. Valladolid: Universidad de Valladolid. 